$\begin{array}{ll} & \text { Etnográfica } \\ \text { etnográfica } & \text { Revista do Centro em Rede de Investigação em }\end{array}$

Antropologia

vol. 25 (1) | 2021

Vol. $25(1)$

\title{
El futuro de la esperanza: el "problema de los jóvenes” en la urbanización de una villa en el Gran Buenos Aires
}

The future of hope: "youth problem" in the urbanization of a shantytown in Great Buenos Aires

\section{María Cecilia Ferraudi Curto}

\section{OpenEdition}

\section{Journals}

\section{Edición electrónica}

URL: https://journals.openedition.org/etnografica/8712

DOI: 10.4000/etnografica.8712

ISSN: 2182-2891

\section{Editor}

Centro em Rede de Investigação em Antropologia

\section{Edición impresa}

Paginación: 73-93

ISSN: 0873-6561

\section{Referencia electrónica}

María Cecilia Ferraudi Curto, «El futuro de la esperanza: el "problema de los jóvenes" en la

urbanización de una villa en el Gran Buenos Aires», Etnográfica [En línea], vol. 25 (1) | 2021, Publicado

el 05 marzo 2021, consultado el 28 enero 2022. URL: http://journals.openedition.org/etnografica/8712 ; DOI: https://doi.org/10.4000/etnografica.8712

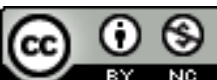

Etnográfica is licensed under a Creative Commons Attribution-NonCommercial 4.0 International License. 


\section{El futuro de la esperanza: el "problema de los jóvenes" en la urbanización de una villa en el Gran Buenos Aires}

\section{María Cecilia Ferraudi Curto}

En este artículo, me propongo reflexionar sobre "el problema de los jóvenes" tal como se presentó durante mi etnografía. A partir de una pregunta por la política, me interesé por la urbanización de una villa de La Matanza considerada emblema de las políticas urbanísticas durante el kirchnerismo. El "problema de los jóvenes" cobró importancia para mí porque les importaba a mis interlocutores en el barrio. En este artículo, intento mostrar cómo se entrelazan diferentes relaciones entre la población y el Estado en la elaboración de dicho problema. Se trata de una manera de responder tanto a las miradas que se centran sólo en el Estado carcelario como a aquellas que enfocan exclusivamente hacia las políticas redistribucionistas de un Estado populista, para indagar cómo diferentes políticas estatales son apropiadas por diferentes actores locales, respondiendo a (y reforzando) las heterogeneidades sociales en un contexto de inestabilidad persistente.

PALABRAS CLAVE: juventud, Estado, villa, heterogeneidades, Argentina.

The future of hope: "youth problem" in the urbanization of a shantytown in Great Buenos Aires - In this article, I intend to reflect on "the problem of youth" as it was presented during my ethnography. From a question about politics, I got interested in the urbanization of a shantytown in La Matanza considered an emblem of urban policies during the Kirchner governments. The "problem of youth" became important to me because it mattered to my interlocutors in the neighborhood. In this article, I try to show how different relationships between the population and the State are intertwined in the elaboration of this problem. It is a way of responding to both the views that focus only on the prison State and those that focus exclusively on the redistribution policies of a populist State, to investigate how different State policies are appropriated by different local actors, responding to (and reinforcing) social heterogeneities in a context of persistent instability.

KEYWORDS: youth, State, shantytown, heterogeneities, Argentina.

FERRAUDI CURTO, Maria Cecilia (mceciliafc@hotmail.com) - Consejo Nacional de Investigaciones Científicas y Técnicas, Conicet/IDAES - Universidad Nacional de San Martín, Argentina. 


\section{INTRODUCCIÓN}

Pensar a los "jóvenes" como un "problema" ha devenido un lugar común en Argentina (y no sólo aquí). ${ }^{1}$ Desde hace décadas, numerosas investigaciones dan cuenta de las juventudes a la luz de transformaciones socioeconómicas, culturales y tecnológicas que impactan sobre trayectorias de vida, legados y horizontes, redefiniendo los modos de categorizar y vivir las etapas del ciclo vital, así como las relaciones entre categorías etarias (Chaves 2009). Sin embargo, desde ciertos discursos sociales, amplificados por los medios de comunicación, los modos de procesar esas transformaciones (atravesados por lógicas de poder) conducen a plantear la cuestión como un "problema de los jóvenes” (Chaves 2005; van Raap 2016). El diagnóstico se exacerba frente a las clases populares.

Las ciencias sociales intentan mostrar los límites de las perspectivas "adultocéntricas” (Alvarado y Vommaro 2010; Chaves 2009). Para ello, se aproximan a las experiencias de distintos grupos juveniles (inicialmente inspiradas en los estudios culturales británicos). A la vez, buscan desnaturalizar las categorías etarias para pensarlas histórica y relacionalmente (Bourdieu 1990).

En Argentina, la juventud como categoría sociocultural está asociada a los años 60. Si solemos vincular su emergencia con la ampliación del acceso a la universidad, el nacimiento del rock nacional y la radicalización política, Manzano (2017) analiza la formación de un espacio de consumo cultural diferenciado y la masificación del colegio secundario como soportes de una experiencia etaria homogénea. En los años 70, los grupos juveniles serían identificados como amenaza no sólo por la radicalización política sino también por desplegar sociabilidades alternativas (en torno de la sexualidad y el consumo de drogas), constituyéndose en víctimas privilegiadas de la violencia estatal represiva.

En la primavera democrática, la juventud, concebida como símbolo de libertad y futuro, empieza a conformarse como objeto de políticas públicas. Organismos estatales específicos surgen propiciados por la declaración de Naciones Unidas del Año de la Juventud (1985). Pero los proyectos se ven interrumpidos por la crisis hiperinflacionaria. Posteriormente, la cuestión juvenil se reconfigura como parte de la concentración y descentralización de las políticas públicas en el marco de la reforma neoliberal realizada por el gobierno de

I Si bien el planteo de Grossberg sobre la reconfiguración hegemónica en Estados Unidos excede ampliamente mi recorrido, inspira las inquietudes que guían este análisis: "una contradicción visible está emergiendo entre la celebración y la guerra contra los chicos [kids], con esta última ganando terreno rápidamente en los últimos treinta años. Esta guerra $[\ldots]$ presagia una reconfiguración profunda de la sociedad estadounidense. La guerra contra los chicos no puede ser explicada empíricamente en términos de escuela, familia, cultura juvenil, etc. Tampoco puede ser vista como una agenda política, a pesar de que es la consecuencia de las luchas políticas contemporáneas. Para entender esta guerra, necesitamos repensar la política como una disputa sobre las estructuras profundas de la modernidad estadounidense" (Grossberg 2005: 11). 
Menem (1989-1999). Emerge la figura del "ni ni" como modelo para abordar la problemática juvenil: ante el deterioro de las instituciones estatales y la crisis del mundo laboral, el foco se coloca en los jóvenes que ni estudian ni trabajan, apuntando a mitigar los efectos del ajuste (van Raap 2016). Hacia fines de la década, una figura juvenil escandalizadora emerge en la escena pública: "los pibes chorros" [jóvenes ladrones], vinculados a modalidades desorganizadas y violentas de delito callejero (Kessler 2004; Míguez 2002). ${ }^{2}$ Si bien este tipo de delincuencia gana protagonismo en los medios, las cuestiones más preocupantes se vinculan con la desocupación y el empobrecimiento que cobran gran visibilidad en torno de 2001 .

Luego de la crisis de la convertibilidad, los gobiernos kirchneristas (20032015) introducen cuestionamientos a las políticas neoliberales y amplían el discurso de derechos. Respecto de la niñez y juventud, esta perspectiva se concreta en la promulgación de la Ley 26.061/2005, que sustituye la concepción tutelar vigente desde 1919, siguiendo los lineamientos de la Convención Internacional sobre los Derechos del Niño de 1989 (Grinberg 2013). Simultáneamente continúan las políticas enfocadas orientadas a la "empleabilidad" de los jóvenes, en tanto la recuperación económica no logra incorporar a franjas significativas de población al trabajo estable (van Raap 2016). ${ }^{3}$ En la combinación entre procesos de deterioro social de largo plazo, recuperaciones socioeconómicas parciales y políticas públicas reparadoras de variado alcance, se producen heterogeneidades crecientes de las clases populares a la vez que se refuerza la frontera simbólica entre "trabajadores" y "pobres" (Semán y Ferraudi Curto 2016). Por último, luego del conflicto con los productores agropecuarios en 2008, el kirchnerismo profundiza otra perspectiva sobre los jóvenes centrada en la politización (cuyas raíces se remontan a las movilizaciones en 2001-02 e incluso a los años 70). Ante la polarización del campo político, la Cámpora adquiere centralidad como organización juvenil del kirchnerismo (Vázquez 2013). Mientras tanto, la creciente preocupación pública en torno de la "inseguridad" (Kessler 2009), fomentada desde los medios de comunicación, conduce a una demanda punitivista que, entre otras consignas, exige bajar la edad de punibilidad.

2 A lo largo de estos años, en América Latina, la cuestión de los jóvenes se ha asociado a la emergencia de "pandillas" (Baird y Rodgers 2015).

3 En tanto privilegia la cuestión del trabajo, esta perspectiva implementada por el kirchnerismo se diferencia de las políticas públicas analizadas por Raposo y Aderaldo (2019), en Brasil y Portugal. Si bien todas ellas comparten la preocupación por la cuestión social (y vinculan a los jóvenes de clases populares con la violencia callejera), estas últimas enfocan en la cultura como eje. Además, los autores la consideran parte de una gubernamentalidad neoliberal renovada, basada en el "empoderamiento", la “resiliencia” y el "protagonismo juvenil”, que responsabiliza a los propios jóvenes, pasando de ser “jóvenes problema” a “jóvenes solución”. Aquí, en cambio, los jóvenes siguen bajo el cuidado (y la autoridad) de los adultos, teniendo la autonomización como horizonte. 
Frente a este escenario, aquí me centro en los modos en los que diferentes actores abordan la cuestión juvenil en un barrio periférico del Gran Buenos Aires entre 2007 y 2015. Como modo de relativizar el "problema de los jóvenes" como categoría dada, me propongo analizar cómo diferentes definiciones de la cuestión se despliegan (en discursos y prácticas) a partir de articulaciones específicas de actores (y sus conflictos) en una villa [favela] del conurbano en proceso de urbanización.

Me acerqué a una villa de La Matanza para analizar cómo sus habitantes vivían la política. A partir de concebir la política como categoría etnográfica (Peirano 1997), me dejé guiar por ellos. Así tomé la urbanización como eje. Una vez allí, solía toparme con situaciones en las que los jóvenes eran objeto de preocupación e intervención por parte de diferentes actores localmente significativos (párroco, dirigente barrial, integrantes de organizaciones y otros habitantes locales). Por ese motivo, intento explorar esta inquietud que se volvió importante para mí porque era importante para mis interlocutores. Para ello, relataré varias escenas de mi etnografía junto con algunas reflexiones preliminares sobre los modos en los que la cuestión de los jóvenes es elaborada localmente como problema. ${ }^{4}$

En términos más generales, intento discutir dos visiones sobre la relación entre Estado y clases populares. Por un lado, el diagnóstico sobre un Estado carcelario como respuesta a la ampliación de la pobreza ha tendido a popularizarse en América Latina, retomando los análisis de Wacquant (2010) sobre EEUU para criticar la respuesta punitivista. Quizá un avance en esta discusión pueda realizarse desplazando la mirada de los jóvenes hacia la forma como los adultos los constituyen como problema y sus respuestas (Gentile 201 lb). Quizá también sea un aporte alejarse de los modos de construir el problema desde el centro (el Estado nacional o los medios masivos de comunicación) para analizar cómo se concreta localmente. Por otro lado, se ha consolidado una imagen de los "gobiernos progresistas" de la región como una actualización del Estado populista que centralizadamente aplica políticas redistributivas, diferenciándose de la versión clásica por la pluralización de las categorías de derecho. Esta mirada unificada del Estado oculta las diferentes exploraciones de sus posibilidades (y sus límites) en variadas articulaciones locales específicas. ${ }^{5}$ A la vez, al concebirlo centralizadamente, tiende a magnificar el poder

4 Realicé trabajo de campo en el barrio entre junio de 2007 y octubre de 2009 para mi tesis doctoral. Posteriormente, mantuve contacto con algunos habitantes, especialmente a través del Programa Envión-Podés orientado a los jóvenes de 12 a 21 años (entre 2013 y 2017).

5 Este análisis se inspira en la perspectiva thompsoniana, retomada críticamente por Roseberry: "Si concebimos el proceso hegemónico y el marco discursivo común como (inarticulados pero necesarios) proyectos estatales más que como logros estatales, podremos mejorar nuestra comprensión de la 'cultura popular' y la 'formación estatal' en relación entre sí. [...] El campo de fuerza es mucho más complejo [que la oposición entre lo dominante y lo subordinado] en tanto leyes, dictámenes, [continua] 
del gobierno nacional tanto para hacer el Estado como para hacer la sociedad. Frente a estas visiones contrapuestas sobre Estado y clases populares, resulta complicado operar una síntesis. Más bien, sería posible sostener una fragmentación de las agencias estatales como modo de responder a (y reforzar) las heterogeneidades sociales, que muestra diferentes articulaciones locales como respuestas situadas y parciales frente a un horizonte estructural de incertidumbre. Siguiendo esta línea, aquí intentaré mostrar diferentes formas de "barrialización del Estado" (Ferraudi Curto 2014) en una villa del Gran Buenos Aires. ${ }^{6}$ Llamados a desafiar fuerzas muy superiores (y reconociendo sus límites), los actores locales buscan imaginar atajos para vivir mejor.

\section{LA URBANIZACIÓN COMO EMBLEMA}

Como sintetizó el intendente cuando la presidenta Cristina Kirchner visitó el barrio en 2012, la urbanización de Villa Torres es un "emblema" de las políticas públicas del kirchnerismo. Durante el trabajo de campo, la importancia de la urbanización atravesaba las diferentes tramas locales, material (por los recursos que movilizaba) y simbólicamente (porque revitalizaba esperanzas de progreso asociadas a la casa propia). Según el relato difundido sobre el proceso, su éxito estaba asociado a una combinación entre "compromiso del barrio" y "compromiso del Estado". Para entender las relaciones entre sectores populares y Estado en Villa Torres, es preciso comenzar por la urbanización.

Los orígenes de la misma son colocados en 1999 cuando los "hijos del barrio" tomaron tierras consideradas parte del mismo por una política de regularización dominial entonces vigente. Gracias al apoyo del párroco, el grupo comenzó a organizarse para reclamar al Estado. Por el asesoramiento de dos personas que habían participado de los asentamientos de La Matanza en la década de 80, los implicados demandaron por la "urbanización". En un contexto marcado por masivos cortes de ruta en La Matanza, ${ }^{7}$ el municipio intentó contener el reclamo urbanístico a través de (escasos) recursos: un arquitecto del municipio, algunos subsidios para los desocupados, materiales para construir y

programas y procedimientos del Estado central son aplicados en regiones particulares, caracterizadas por patrones distintivos de desigualdad y dominación, los cuales son productos sociales de procesos históricos que ya relacionaban centro y localidad" (1994: 365).

6 Aquí el foco del análisis está colocado en las iniciativas de actores locales. Si bien la escuela es importante como institución orientada a niños y adolescentes (y prácticamente todos los jóvenes del barrio han transitado por alguna de ellas), aquí sólo aparece en relación con dichas iniciativas.

7 Ubicado al oeste de la Capital, La Matanza es el municipio más extenso y poblado del conurbano. Según el censo 2010, cuenta con 1.775.816 habitantes: concentra el 17,9\% de la población del GBA (secundado por Lomas de Zamora con el 6,2\%) y un 4,4\% de la población nacional. Asentamiento de numerosas fábricas desde mediados del siglo xx, a partir de la apertura económica en los años 70 sufrió un creciente deterioro de la situación social. Entre 2000 y 2001, los cortes de ruta mostraron la masificación de las protestas "piqueteras" (por el problema de la desocupación) en el centro político del país. 
una ordenanza municipal anunciando la "urbanización". Entonces, arquitecto y habitantes movilizados realizaron un censo barrial y un relevamiento del hecho existente, para volver legible el reclamo desde la lógica estatal. Posteriormente, el censo se convertiría en la prueba del derecho a una casa.

Luego de la crisis de diciembre de $2001,{ }^{8}$ las autoridades nacionales multiplicaron los recursos disponibles para enfrentar la "emergencia social": junto con la masificación de los subsidios para los desocupados, se implementaron políticas habitacionales inicialmente dispersas y luego centralizadas en el Plan Federal de Viviendas (2005). El municipio más populoso del conurbano (y localización de organizaciones de desocupados masivas) fue considerado un distrito clave. Para los actores involucrados en la urbanización de esta villa, el "quilombo [desorden]" de 2001 fue una "oportunidad".

Si bien el Programa Federal implicó la centralización de la política urbanística, el Subprograma de Urbanización de Villas y Asentamientos introdujo formas de descentralización municipal. En La Matanza, este programa condujo a la creación de una Unidad Ejecutora a cargo de José, el dirigente local que se constituyó como tal en la urbanización de Villa Torres, y del arquitecto municipal que había coordinado las primeras obras. A partir de este dispositivo institucional, el grupo logró combinar los recursos de numerosos planes estatales - Promeba, Plan de Emergencia Habitacional, Programa Federal, Subprograma de Urbanización, Plan Mejor Vivir, Plan Dignidad (provincial) -. Esta estatalización del barrio también implicó una "barrialización del Estado" (Ferraudi Curto 2014). Por un lado, la urbanización fue apropiada por los actores locales, tomando características singulares que permitieron su gestión cotidiana. Por otro, su éxito requirió su presentación como "emblema" frente a funcionarios, profesionales y dirigentes de otros barrios. Responder al "problema de los jóvenes" es parte de su legitimación tanto "adentro" como "afuera" del barrio. A la vez, excede a la urbanización... y nos ayuda a mostrar las complejidades de la relación entre sectores populares y Estado durante el kirchnerismo.

\section{LO VAN A MATAR}

Cuando iba a Torres, solía almorzar en el puesto de Vicenta: un carrito asentado junto a la terminal del colectivo enfrente de la villa. Ella vivía en el barrio

8 En diciembre de 2001, el presidente De la Rúa (1999-2001) renunció en el marco de protestas masivas. La convertibilidad (paridad del peso argentino con el dólar, sostenida primero con privatizaciones y luego con deuda pública y ajuste fiscal) acumulaba cuatro años de recesión. A los "cortes de ruta" por la desocupación, se sumaron "cacerolazos" de pequeños ahorristas cuyos depósitos habían sido inmovilizados por decreto en diciembre y "saqueos" en las periferias de las grandes ciudades. Ante la declaración del estado de sitio, una manifestación masiva frente al Congreso clamó contra los políticos: "Que se vayan todos". Luego de diez días de inestabilidad, y de la declaración del default, Duhalde asumió el gobierno provisional. 
hacía muchos años y me interesaba seguir sus peripecias por una casa después de separarse (y dejar la casa donde había sido censada). En mis visitas, también surgían otros temas de conversación.

Una vez vimos juntas cómo la policía detenía a un "pibe" 9 en la ruta. Hacía tiempo, una camioneta de la policía provincial estaba apostada a metros de nosotras, supuestamente para evitar que los pibes robaran a los automovilistas detenidos en el semáforo. Vicenta comentó que era la segunda vez que llevaban a ese chico. "La próxima lo van a matar", sentenció.

Quedé muda, enojada por lo que sucedía y por la respuesta de Vicenta. Le había escuchado comentarios similares cuando los familiares de un chico muerto por la policía cortaron la ruta (junto con una organización local): “¿Por qué no hicieron algo antes?", los amonestaba a la distancia aduciendo que todos sabían en qué "andaba" el pibe. Pero esa crítica me había resultado menos perturbadora que su presagio. Un tiempo después, otro pibe fue detenido frente a nosotras. Entonces, ya pude dialogar con ella. Vicenta me dijo que no sabía por qué la mamá no lo mandaba a una granja (de rehabilitación de las drogas): "Si la familia no hace algo, la policía termina matándolo porque se cansa de llevarlo detenido y volver a encontrarlo en la calle enseguida". En otra oportunidad, me contó cómo una madre había pedido a la policía que se llevara a su hijo porque ya no sabía cómo controlarlo. También la escuché discutir con su hijo sobre una cuestión similar: un chico vecino había sido detenido en un allanamiento; ella quería defenderlo para que no quedara preso porque "no está metido en nada, pero no tiene familia que lo defienda"; su hijo insistía con que no se metiera, que no era asunto de ellos.

En la recurrencia variable de las situaciones, fui entendiendo la perspectiva de Vicenta en términos de evaluaciones morales situadas que ponían en juego una concepción sobre lo deseable y lo obligatorio (dentro de los límites de lo posible).${ }^{10}$ Primero, la diferencia fundamental era marcada por el modo de vida que ella atribuía al pibe: "estar metido" o "andar" eran las formas de referirse a ello. Como señala Kessler (2004), las calificaciones negativas sobre los pibes no siempre se basan en prácticas ilegales: pueden referir al robo, al consumo de sustancias ilícitas o simplemente al "bardo" (hacer ruido, beber alcohol) en las esquinas. Como muestran Bermúdez (2014) y Diez (2009),

9 La categoría "pibe" es una forma coloquial de referir a los niños y jóvenes en Argentina, atribuyéndoles cierta "calle" (por oposición a "nene").

10 En la elaboración de las perspectivas locales, me guío por Pitt-Rivers: "Tuve que construir a partir de la observación escalas de preferencia y de obligaciones con la que construir la trama de deseos y sanciones desde la cual los individuos determinan sus conductas. Expresé el resultado como 'valores'. [...] Los valores no son a mi entender puramente éticos, sino, en primer lugar, cognitivos. Son conceptos cuyo contenido ético es parte integral de ellos y llega a ser manifiesto sólo atendiendo al contexto, aportación de la etnografía" (1989: 34). A la vez, los juicios morales no sólo guían la propia acción, sino también operan continuamente en la evaluación de las acciones de los demás, tal como muestra Firth (1971). 
la vida de los pibes es valorada diferencialmente según la evaluación de sus prácticas recientes: estar o andar son verbos que indican esas variaciones a lo largo del tiempo. ${ }^{11}$ Segundo, Vicenta identificaba una lógica en el accionar policial. Las detenciones funcionaban como advertencias. Ante lo que era percibido como inacción de la familia y/o del sistema judicial, la legalidad no era un límite para los oficiales. En estas situaciones, su respuesta previsible era dar muerte al joven en cuestión. Para Vicenta, la práctica ilegal del Estado no era objeto de denuncia, sino que, asumiendo la "monstruosidad" del aparato estatal (Zarazaga 2017), se trataba de movilizar tácticas locales de protección. No todos los actores locales compartían su juicio (y algunos incluso protestaban), pero ella explicitaba una concepción que no sólo refería a la valoración diferencial de las muertes, sino también estipulaba límites para la eficacia del propio accionar (en términos de poder respecto de los agentes estatales y frente a la irrevocabilidad de la muerte). Tercero, para Vicenta la familia era quien debía cortar la secuencia perversa. Otros seres cercanos también podían ayudar, pero no eran vistos como responsables de la situación, y su intervención era objeto de controversia. En definitiva, no había condena a la policía por matar a un pibe sino a la familia por no sacarlo de esa situación mortal.

\section{HIJO, TE AMO}

Así se llamaba la iniciativa que un grupo de familiares de jóvenes afectados por el consumo de drogas había emprendido con el apoyo del párroco local. A su manera, el nombre evocaba la lógica expuesta por Vicenta. En ambos casos, la familia era la vía para "rescatar" a los pibes y la madre era la figura central.

El padre Tuchi es un actor destacado del barrio, donde creció, donde vive su familia y donde él ejerce como párroco desde 1997. Las primeras reuniones luego de la toma en 1999 se organizaron en su parroquia. Guió el reclamo urbanístico hasta que tomó vuelo. Después, lo siguió a mayor distancia, mientras su cuñada se desempeñaba como secretaria de la Unidad Ejecutora municipal. De un modo semejante, también encaró el problema de la droga entre los jóvenes.

Según cuenta, durante años madres se acercaban a él para pedirle consejo. A inicios de siglo, el panorama se oscureció por la llegada del paco. ${ }^{12}$ En 2006, el

11 Las valoraciones diferenciales sobre la muerte violenta también se observan en otros espacios sociales, ayudando a entender las versiones cruzadas sobre la moralidad de las víctimas que circulan durante los procesos de reclamo por justicia ante los poderes públicos (Gayol y Kessler 2017).

12 El término "paco" refiere en Argentina a una sustancia obtenida de los desechos del procesamiento de clorhidrato de cocaína. En tanto es considerada muy nociva (y su consumo se extendió por su bajo costo y la difusión de las "cocinas" en el conurbano), diferentes grupos se movilizaron contra su venta, destacándose la red Madres contra el paco por la vida. Como en Hijo, te amo, aquí también la figura materna es tomada para identificarse. 
padre Tuchi decidió hacer un Via Crucis por el barrio, con la consigna de luchar contra la droga. En el recorrido, se detuvieron frente a la casa del "transa" (vendedor de drogas ilegales) más importante del barrio y varias madres contaron allí sus historias de sufrimiento. A partir de entonces, el cura habilitó un espacio para alojar a los jóvenes en recuperación en su casa. No disponían de un protocolo para tratar a los pacientes, sino que aprendieron en la propia experiencia. A diferencia de otros espacios institucionales de tratamiento (como las granjas mencionadas por Vicenta), ellos no separaban al joven de su entorno. ${ }^{13}$ Enseguida, el espacio con que contaban se mostró insuficiente. A medida que la urbanización se fue concretando, la vieja escuela abandonada (ubicada enfrente de la parroquia) fue solicitada por el padre Tuchi para la institución. Dada la historia compartida, y la centralidad del problema para la vida local, no pudieron negarle el lugar, a pesar de la escasez de espacio.

En noviembre de 2009, el hogar Hijo, te amo fue inaugurado (junto con el asfalto de la calle central del barrio) en un acto que contó con la presencia del intendente Espinoza, el líder distrital y entonces vicegobernador de la Provincia Balestrini, ${ }^{14}$ el dirigente de la urbanización y el párroco como figuras centrales. Al lado del hogar, también se montó una escuela de oficios que, con el respaldo de la UOCRA (Unión de Obreros de la Construcción de la República Argentina), realizaba cursos de albañilería, carpintería, plomería y panadería para los jóvenes del barrio a partir de un plan de formación del gobierno nacional. En un barrio donde la distribución de lugares para vivir constituía una cuestión conflictiva que implicaba un trabajo pormenorizado de funcionarios y habitantes, la cesión del predio de la vieja escuela barrial para las iniciativas gestionadas por la iglesia mostraba el fortalecimiento local de dicha institución bajo el liderazgo del párroco. ${ }^{15}$

13 Surgidas luego de la apertura democrática en un contexto de visibilización del problema de las drogas en Argentina, y popularizadas a partir de la institucionalización del problema durante los años 90, las granjas constituyen dispositivos terapéuticos comunitarios de aislamiento, basados en una postura abstencionista - muchas veces vinculados con instituciones religiosas -. En discusión con este modelo, desde 2008, tiene lugar una reformulación parcial de las políticas sobre drogas, basada en una perspectiva de derechos humanos, reducción de riesgos e inclusión comunitaria. Dentro de este marco, en 2013 las iniciativas de los curas villeros (entre ellas, la del padre Tuchi) fueron reconocidas estatalmente bajo la nominación Hogares de Cristo (Camarotti y Güelman 2017).

14 Alberto Balestrini fue intendente del distrito entre 1999 y 2005, cuando dejó a su sucesor, Espinoza, para asumir como presidente de la Cámara de Diputados de la Nación. Cuando llegamos al barrio existían rumores sobre su candidatura a la vicepresidencia, a la gobernación bonaerense o a la vicegobernación - cargo por el cual fue electo en octubre de 2007.

15 La vieja escuela fue abandonada a partir de la construcción de una nueva. Ubicada en el límite entre el "barrio viejo" y el "barrio nuevo", esta edificación mostraba espacialmente cómo la educación continuaba representando el tránsito a la modernidad, desde la mirada estatal. Si bien los pobladores parecían valorar la escuela como vía para ampliar las posibilidades de "salir", solían diferenciarla de otras cercanas. Por eso, muchos preferían llevar a los hijos a una escuela "afuera del barrio". 
A la vez que concentraba, amplificaba y encarrilaba diversas inquietudes locales hacia la conformación de reclamos colectivos, el cura buscaba conducir la movilización hacia la elaboración de respuestas institucionales frente a cada problema. En ello, llamaba a la intervención de diferentes agencias estatales, combinaba otras fuentes de recursos ${ }^{16} \mathrm{y}$ procuraba amplificar los márgenes de acción local, en tanto confiaba en la experimentación colectiva como fuente del saber. Así las políticas estatales eran apropiadas bajo modelos de organización que los mismos actores gestaban en su acción.

Una dinámica similar se desplegó en la implementación del Programa Envión a partir de 2009, aunque esta vez la iniciativa provino del Estado (Ferraudi Curto, Moriconi y Peralta 2017). Orientado a los estudiantes secundarios en riesgo de "desengancharse" de la escolaridad obligatoria, el programa provincial-municipal articulaba con diferentes entramados organizativos locales, particularizándose en su implementación. En Villa Torres, los funcionarios seleccionaron a la parroquia como sede, en reconocimiento (y reforzamiento) de su centralidad. Para los beneficiarios, el programa implicaba un incentivo económico mínimo, la realización de talleres de formación menos estructurados que la currícula escolar (deportivos, culturales, recreativos) y el acompañamiento individualizado a través de un equipo técnico interdisciplinario y "operadores" (jóvenes que ya habían pasado por la misma situación y eran promovidos desde el programa). Un profesor del secundario barrial era parte del mismo, facilitando la articulación entre escuela y parroquia. Según su relato, dicha institución enfrentaba el problema de una matrícula decreciente, que extremaba el conflicto entre dos posturas docentes: el director pretendía un modelo flexible para sostener la escolaridad de los jóvenes (y evitar el cierre de cursos) y un grupo de profesores se oponía a lo que veía como ausencia de límites. En 2015, el caso de un estudiante que, en un episodio violento, había golpeado al director con el asta de la bandera, era tomado como prueba de la ineficacia de sus métodos. En ese contexto, el Programa Envión contribuía a sostener la postura retentiva del director, a pesar de sus detractores, pero parecía insuficiente ante la compleja problemática que atravesaba la escuela.

Hacia el fin del gobierno de Cristina Kirchner, el programa también empezó a recibir críticas de ciertos pobladores como modo de "criar vagos". Incluso en un lugar donde las políticas públicas enfocadas eran centrales, la oposición entre trabajo y vagancia (asociada al recurso a los programas estatales) daba cuenta de diferenciaciones profundas dentro de las clases populares. Si bien la cuestión juvenil era un problema reconocido dentro del barrio, las respuestas no lograban tanta aprobación. Quizá otros malestares hacia los modos de concretar las políticas públicas localmente se manifestaran allí.

16 Entre otras fuentes, el párroco mantenía un vínculo estrecho con Cáritas, articulaba con diferentes ONG e incluso contaba con el apoyo de un Programa del PNUD. 
En definitiva, a partir de la parroquia, se habían estructurado varias iniciativas (entre ellas, la misma urbanización). No se trataba simplemente del peso de la iglesia católica como institución, sino de un modo específico de conducirla localmente. ${ }^{17}$ El padre Tuchi propiciaba experimentaciones tendientes a ampliar los márgenes de acción locales, estirando los límites impuestos con esfuerzo e imaginación. Para ello, se ocupaba de multiplicar las fuentes de recursos y, en lo posible, encarrilarlos por la parroquia, fortaleciendo su posición como centro de la vida barrial. Un modelo de familia orientado hacia los hijos (y enmarcado en la religión católica) solía guiar sus acciones. Aunque protestar era una posibilidad dentro de su repertorio, el párroco intentaba antes explorar otras alternativas menos confrontativas. Si bien buscaba expandir los márgenes de acción locales, no todas las iniciativas lograban su apoyo. Mientras cooperativa y parroquia mantenían esas tensiones bajo un reconocimiento mutuo, otra organización se había distanciado de este entramado local dominante. Significativamente, las tres vehiculizaban respuestas para los jóvenes.

\section{CORTAR LA RUTA}

Una de mis charlas con Vicenta surgió al observar una protesta en reclamo por el asesinato de un joven, en tanto familiares y amigos acusaban a la policía provincial de la muerte. Mientras Vicenta cuestionaba la utilidad de este tipo de acciones, una organización local había respaldado el corte de ruta. ${ }^{18}$

Se trataba de un centro de día organizado por Mariana junto con sus dos hijos de 16 y 21 años. Llevaban adelante diferentes talleres para jóvenes de la zona (entre ellos, uno dirigido a las llamadas "niñas madres"). Trabajaban centralmente el tema de las adicciones. Además, el hijo mayor era referente de "proyectos" en el Consejo Consultivo de Juventud provincial, vinculado al Ministerio de Salud.

Todos habían empezado participando en la parroquia: los hijos en la copa de leche ${ }^{19}$ la madre en el armado de la cooperativa para la urbanización. Pero, según dicen, se separaron por la "politización", distinguiendo entre política

17 El párroco se reconoce como parte de una corriente de la iglesia, los curas villeros. Un mural en el comedor de la parroquia muestra la figura del padre Mugica, fundador de la corriente, asesinado por la Triple A (un grupo parapolicial de la derecha peronista) en 1974.

18 En Argentina, la cuestión de la violencia institucional se ha constituido en objeto de problematización y denuncia pública, desde mediados de los años 80. Si los organismos de derechos humanos han sido un actor central en esta elaboración, Pita (2010) analiza la importancia de la figura del "familiar" en la construcción de los casos de "gatillo fácil", mostrando repertorios populares que recurren a la broma y al insulto en las manifestaciones como ritual de degradación de dicha fuerza pública.

19 En la parroquia, la asistencia alimentaria es una de las actividades más antiguas (que precede al padre Tuchi). El comedor, fundado en 1992 para cincuenta personas, llegaba a casi quinientas en 2009. Por las tardes se ofrece merienda a los niños (copa de leche). 
partidaria y política social. ${ }^{20}$ Desde entonces, consiguieron el "padrinazgo" de una organización de una localidad cercana (llamada "kiosco juvenil") ${ }^{21}$ y empezaron a tejer redes en torno de las políticas orientadas a niñez y juventud. ${ }^{22}$ Si bien Mariana siguió acompañando sus iniciativas, sus hijos cobraron protagonismo en la organización de las actividades y en el vínculo con diferentes organismos estatales. Costumbres Argentinas fue el nombre que eligieron para su organización, en alusión a un tema del rock nacional que reivindica "decir ino!". Ellos incorporaron los reclamos acallados por los compromisos de las otras organizaciones locales: ya fuera contra la autoridad policial, en el caso de los asesinatos de jóvenes, o contra la autoridad eclesiástica, en el caso de abortos clandestinos. Desde un discurso modernizador, buscaban generar conciencia en los jóvenes, a distancia de religión y partidos políticos. En ese sentido, habilitaban prácticas locales no legitimadas por las instituciones dominantes del barrio, es decir, mostraban concepciones alternativas y resultaban disruptivos tanto localmente como en relación con ciertas agencias del Estado (como la policía). Pero encontraban ventanillas estatales para sostener sus iniciativas.

\section{HABLAR SU MISMO LENGUAJE}

La urbanización también incorporaba la recuperación de los pibes dentro de sus objetivos. Desde mi primera visita (para un diagnóstico del barrio solicitado por el gobierno provincial), el tema fue parte de la presentación de la urbanización. A pedido del dirigente barrial, el encargado de la cooperativa de demolición contó su trabajo con los pibes. ${ }^{23}$ Según dijo, llamaron a un "chorro" (ladrón) reconocido en el barrio que acababa de salir de la cárcel para que los comandara: si él no se robaba todo, nadie iba a robar. Así lograron el respeto

20 Si bien ellos buscaban distanciarse de banderas partidarias, y eso les permitía trabajar localmente, eran objeto de desconfianza. Entre otras sospechas, un militante local del PJ (Partido Justicialista, gobernante) refería a su cercanía con "los piqueteros".

21 Fundada en 1994, la organización comenzó abordando cuestiones vinculadas al consumo de drogas entre los jóvenes a partir de una perspectiva de reducción de daños aprendida en Chile. Luego, cobró visibilidad mediática y local. Hoy es una sede del Programa Envión.

22 Mientras el discurso tutelar colocaba el centro de las intervenciones en el plano judicial (librándolas a la discrecionalidad de los jueces), el predominio del "enfoque de derechos" implicó la emergencia de variados marcos normativos, entramados institucionales y políticas públicas específicas orientadas a niñas, niños y adolescentes, dando lugar a diferentes procesos según los distritos (Villalta y Llobet 2015). Para Mariana y sus hijos, estas dinámicas estatales habilitaron la posibilidad de obtener recursos por vías alternativas, especializándose en la cuestión juvenil.

23 Las cooperativas se conforman de acuerdo a lo estipulado por los programas estatales que subsidian las obras. Esta modalidad de relación entre el Estado y las clases populares se remonta en Villa Torres a los años 90. Hoy se distingue la institución más antigua (formada en esa época) y las más recientes (surgidas del Plan de Emergencia Habitacional lanzado por Kirchner en 2004): la "cooperativa madre", presidida por José; y las "cooperativas hijas". Es decir, la referencia a la familia también permeaba el trabajo en la urbanización. 
de los pibes. Como solía decir el dirigente, se trataba de "hablar su mismo lenguaje" y así "convencerlos" del proyecto. A los "pibes de la esquina", José aseguraba decirles: "ponele que sos el chorro más groso, qué robás: un camión de caudales; cuánto sacás: ¿\$1.000.000? ¿\$2.000.000? Acá ya hay más millones. Y no corrés riesgo. Encima acá entramos todos: vos, tu familia, tu vecino...".

Como el padre Tuchi, José intentaba que los pibes tuvieran alternativas de vida menos riesgosas. Sus opciones no omitían la alusión a la familia, pero privilegiaban los valores de la misma esquina para legitimarse frente a los pibes. Mientras la parroquia nucleó a las madres, la cooperativa destacó el prestigio local de los "chorros" que históricamente habían dominado el barrio. Si bien muchas investigaciones marcaron la ruptura intergeneracional también respecto del delito (como oposición "chorros viejos"/"pibes chorros") (Kessler 2004; Míguez 2002), aquí se expusieron y fortalecieron las continuidades como modo de "rescatar" a los pibes, en una apropiación de las políticas públicas desde lógicas locales específicas.

Por otro lado, la urbanización no sólo recurría al pasado para legitimarse en el barrio, sino que la apuesta central era hacia el futuro, desde una perspectiva modernizadora diferente a la de Mariana y sus hijos. Por ello, el trabajo con los pibes les daba reconocimiento entre los habitantes del barrio. Cuando concurrí a la asamblea general de la organización barrial en 2009, había un clima de tensión latente. El año anterior algunos integrantes de la cooperativa habían sido acusados de ladrones por numerosos vecinos. Además, el conflicto del gobierno nacional con los productores agropecuarios en 2008 había implicado la suspensión temporaria de los recursos para las obras, un esfuerzo considerable de movilización colectiva a la capital y una derrota política para el gobierno que afectaba a la urbanización y a sus actores locales. ${ }^{24}$ Aunque se percibía el malestar, no hubo escándalos durante la asamblea. Más bien, las noticias de obras eran recibidas tibiamente por el público. Sólo cuando la locutora refirió a los pibes y sus logros en la cooperativa (otorgándoles un diploma a cada uno de ellos), la audiencia aplaudió y vivó a los homenajeados. Fue el único momento festivo de la asamblea.

En otras palabras, las iniciativas para los jóvenes no sólo mostraban diferentes lógicas válidas localmente, sino que, paralelamente, eran fuente de legitimidad de las organizaciones locales en un contexto marcado por una reformulación del barrio y las posiciones relativas a partir de la urbanización.

24 Las retenciones a la exportación de commodities fueron un mecanismo central de financiamiento del Estado luego del default en 2001, aprovechando las rentas extraordinarias del sector durante esos años (especialmente, la soja). En 2008, el gobierno nacional buscó imponer una tasa variable vinculada al precio internacional del grano (Resolución 125), pero enfrentó la protesta de los productores agropecuarios sostenida por un amplio apoyo social. La complicada salida del conflicto (y la derrota legislativa del kirchnerismo por el voto del vicepresidente) generó la polarización del campo político (kirchnerismo/anti-kirchnerismo). 
Si la urbanización se sostenía como emblema en tanto lograra conjugar "compromiso del barrio" con "compromiso del Estado", resultaba amenazada continuamente por las posibles acusaciones, denuncias y protestas. Se trataba de un equilibrio inestable que requería renovarse periódicamente. Se combinaban diferentes dispositivos de incorporación de la población local para regular los conflictos: como habitantes, como trabajadores, como socios. Las asambleas de la cooperativa eran uno de los mecanismos para renovar ese equilibrio inestable. Mientras la implementación de las obras daba lugar a suspicacias, la incorporación de los jóvenes en prácticas laborales informales era significada como formación y valorada.

Así, el "problema de los jóvenes" se configuraba localmente de modos variados, dando cuenta de una pluralidad de concepciones sobre la juventud dentro del propio barrio, y de su vinculación compleja con diferentes caras del Estado en el barrio. Como señala Gentile (201 lb), la descentralización y enfoque de las políticas públicas orientadas a la niñez y juventud a partir de los años 90 favorecieron la pluralización de criterios y concepciones sobre la niñez y la inclusión social entre los efectores de los programas. Pero, a diferencia de su análisis, aquí subrayo que las variadas concepciones (y acciones) en torno del "problema de los jóvenes" (vinculando las nociones de familia, barrio, esquina, escuela y trabajo) coexistían en un mismo barrio como modos de apropiación local de las políticas públicas. Mientras la parroquia funcionaba como centro de la vida local, otras iniciativas habían logrado emerger a partir de ella: una había cobrado protagonismo por la importancia de la urbanización; la otra tenía una posición marginal pero altamente visible por disruptiva; todas sostenidas en recursos estatales. Si bien en todas ellas los adultos primaban, en Costumbres Argentinas los jóvenes (y especialmente los hijos de Mariana) adquirieron mayor poder decisorio. En su pluralidad, favorecían diferentes formas de ser joven en el barrio, mientras sancionaban (e intentaban limitar) otras existentes. Entre los diferentes modos de transitar por ellas, aquí enfocaré en el relato de Matías porque regresa sobre la cuestión central de este artículo.

\section{UNA BANERA PARA MI NENA}

Durante mi trabajo de campo, acompañé la conformación de una nueva cooperativa para los pibes: la de paredón. Una vez que algunos habitantes se habían mudado a las casas nuevas, ladrillos, chapas, maderas o nylon fueron utilizados para separar el patio propio y el del vecino. Al verlo, el grupo que encabezaba la urbanización decidió incorporar la realización de paredones linderos. Para justificar el pedido de fondos frente a los funcionarios nacionales, hablaron de la belleza de las casas y del riesgo de que pareciera otra vez una villa. A fines de 2008, nacía la cooperativa de paredón: tres personas que hasta entonces trabajaban en la urbanización "a honores" (por un subsidio de \$250 
por mes), comenzaron a cobrar (\$1400 por mes) por organizar dos cuadrillas de pibes (alrededor de veinte, que cobraban $\$ 50$ por día)..$^{25}$ Aunque también se implementaba en otras cooperativas de trabajo, el pago diario se justificaba específicamente en el caso de los pibes como una forma de desalentar la "joda" nocturna, y a la vez asumirla como práctica frecuente. En realidad, las amonestaciones eran más bien jocosas, excepto cuando los jóvenes pasaban más de una semana sin ir a trabajar. Entonces, no sólo hablaban con los pibes más responsables para que fueran a buscarlos, sino que también avisaban al grupo del padre Tuchi. Matías era uno de los pibes a quien asignaban mayores responsabilidades.

Se trataba de un muchacho de veintitrés años que se había juntado con su novia cuando ella quedó embarazada. Antes, ambos eran "quilomberos": andaban en la "calle", "bardeaban". Ahora, se habían "rescatado": él formaba parte de la cooperativa y tocaba en la murga del barrio; ella lo acompañaba a las movilizaciones mientras cuidaba a la hija de ambos.

En una de nuestras charlas, me contó entusiasmado que pronto le entregarían su casa nueva. Le habían construido una habitación con baño y cocina encima de la casa de sus suegros. La casa venía sin bañera, pero él ya había comprado una para su nena. Ilusionado, se la imaginaba jugando mientras se bañaba.

Su historia me recordó un texto de Rubinich (1998). Los habitantes de un barrio de trabajadores empobrecidos durante los años 90 se habían negado a participar del proyecto de una ONG: construir un retrete en el fondo de sus viviendas para vender abono. Rubinich lo relacionaba con el sueño de la casa propia como horizonte de progreso de los trabajadores en Argentina y su noción de dignidad históricamente aprendida, representada en el baño integrado, para discutir la perspectiva economicista de la ONG. En la historia de Matías, yo veía una continuación de ese horizonte de sentido históricamente reavivado como esperanza por la política de urbanización. Pero no sólo eso. A su manera, Matías también participaba de las presentaciones de la urbanización frente a funcionarios y profesionales que visitaban las obras. Constituía un ejemplo de éxito de la política urbanística con los jóvenes. A la vez, en el relato de Matías se reencontraba la familia, y especialmente la llegada de la hija, como momento de maduración y salida del "bardo", ¿y de la "calle"? (Gentile 2017). ${ }^{26}$ De todos modos, esa amenaza que asechaba a los jóvenes en las esquinas no sólo se vinculaba con el riesgo de recaída...

25 En ese momento, el dólar cotizaba alrededor de \$3,50.

26 Gentile (2017) muestra cómo la calle constituye un "ordenador biográfico" para muchos jóvenes de sectores populares, en un contexto marcado por el debilitamiento de otros ordenadores históricamente significativos como la escuela y el trabajo. En el relato de Matías, se ve la importancia de la calle mientras el nacimiento de la hija opera como punto de inflexión para su "rescate". Aquí lo analizo como transición a la adultez, asumiendo la reversibilidad y la variedad de puntos de pasaje en las sociedades contemporáneas, desde un enfoque biográfico (Casal, García y Merino 2015). 


\section{IGUAL ESE PIBE NO VALÍA NADA}

En 2008, fui al barrio unos días antes de Navidad. Muchos me hablaron de los preparativos para las fiestas. Cuando Matías me acompañaba hacia el colectivo, me contó que dudaba si debería ir a visitar a su familia en una villa cercana, porque estaban esperándolo para "hacerlo cagar" [matarlo]. ¿Por qué?, pregunté.

En varias ocasiones, su papá había sido asaltado por un grupo de pibes que se juntaba en una esquina del barrio. Matías los conocía, aunque eran más chicos y no habían andado nunca juntos. Una vez, uno de los pibes estaba demasiado perdido y se le escapó un tiro que le desfiguró la cara al padre de Matías. Cuando éste se enteró, agarró un arma, fue hasta la esquina y le dio varios tiros al pibe. Pensó que lo había matado, pero lo dejó cuadripléjico. Ahora la familia del pibe lo buscaba a él. Pero, según aseguraba, iba a ir igual en Navidad. "Igual ese pibe no valía nada. Estaba en cualquiera. Yo antes tampoco valía nada. Podía morir y nadie iba a dar nada por mí. Pero me rescaté”, concluyó con una sonrisa.

Al escucharlo, recordé a Vicenta. No sólo la policía podía matar a los pibes que "andaban", en tanto esos actos se apoyaban en el "valor" diferencial de las muertes jóvenes (Bermúdez 2014). Además, si la familia era responsable de proteger a sus miembros, aquí también se veían las obligaciones de los hijos en esos vínculos (y de otros parientes varones). La esquina podía ser un lugar de peligro para algunos habitantes locales. La violencia física, e incluso el uso de armas, eran admitidos en esas circunstancias. Si bien Matías mencionaba el riesgo de venganza, existía un margen de incertidumbre en cuanto a hacerla efectiva (y en sus evaluaciones pesaba el juicio respecto a cómo "estaba" el pibe en comparación consigo mismo). En definitiva, no sólo existían valoraciones diferenciales de la muerte joven asociadas a la categorización diferencial de las personas, sino que las ubicaciones en esta misma categorización podían variar a lo largo del tiempo. Si el "rescatarse" refería a ese pasaje, tampoco era concebido como una ruptura absoluta con el pasado (tal como muestran los modos de organizar la paga de los pibes en la cooperativa y, más detalladamente, Diez 2009). En el juego entre esas categorías inestables, el trabajo personal, familiar y colectivo para "rescatarse" cobraba centralidad. Pero este esfuerzo no era igualmente reconocido por todos los actores implicados.

Según contaba Matías, él había tenido más suerte que sus amigos. Como había engordado después de dejar las drogas, la policía no lo asediaba ni en el barrio ni en el centro del distrito porque no lo reconocía. Sus compañeros de la cooperativa, en cambio, seguían sufriendo el maltrato policial. Mientras localmente el "rescate" podía entenderse como un pasaje importante, aunque relativo, para la policía la categorización diferencial de las personas tenía consecuencias duraderas. Otras categorizaciones estigmatizantes también resultaban persistentes. 


\section{SIGUE SIENDO VILLA}

La transformación de villa a barrio aparecía como imagen idealizada de la urbanización en la prensa y en las presentaciones grupales. La oposición entre antes y después era un modo de narrarse a sí mismos y destacar el éxito de la política urbanística.

Una vez que escribí sobre la urbanización, también yo me vi imbuida en ese juego en el que la urbanización se constituía como emblema (y se sostenía a lo largo del tiempo), aunque pretendiera mostrar sus complejidades. En 2015, hablé de la urbanización frente a un grupo de arquitectos e ingenieros que realizaban un posgrado en políticas urbanísticas. Al terminar mi exposición, hubo diferentes preguntas y comentarios. Entre ellos, un ingeniero que solía pasar frente al barrio cuestionó el éxito de la política porque, a su modo de ver, seguía siendo villa. Cuando una compañera le preguntó por qué decía eso, contestó que los automovilistas evitaban detenerse en ese semáforo porque había pibes que robaban allí.

Sus palabras me impulsaron a escribir este artículo. Primero, remitían a lo que localmente era visto como el "problema de los jóvenes", pero sólo desde el lugar de la amenaza, rememorando los modos en los que los jóvenes de clases populares aparecían en los medios de comunicación - desde una construcción que contribuye a colocar la inseguridad como problema público y la baja en la edad de punibilidad como respuesta exigida al Estado (Gentile 201 la) -. Volví a la conversación con Vicenta desde un lugar diferente. La respuesta policial no sólo se sostenía en la valoración diferencial de las muertes jóvenes tal como era elaborada en el local, sino que se respaldaba en discursos socialmente más amplios centrados en una figura amenazante (que reeditaban el discurso sobre los "pibes chorros"). Segundo, explicitaban cómo ciertos rasgos se constituyen como definitorios en la catalogación de lugares según nuestra tipología urbana previa. En su caso, el accionar de algunos pibes en la ruta bastaba para definir al lugar como villa e implicaba en ello un espacio peligroso (no sólo nadie "entraba" allí, sino que ni siquiera se podía detener en sus cercanías). Por último, abría a una pregunta sobre los límites de la urbanización como política de integración social. ${ }^{27}$ Antes que criticar los puntos de vista ajenos como prejuicio, se trata de reflexionar sobre nuestro presente.

\section{LA URBANIZACIÓN COMO SALIDA}

Históricamente, el horizonte de ascenso social en esta villa se sintetizaba en una frase: "salir del barrio". Frente a esta perspectiva individual (y difícilmente

27 Los debates sobre inseguridad actuales muestran los cuestionamientos a las explicaciones sociológicas típicas (que conectan la inseguridad con el crecimiento de las desigualdades) ante la evidencia de la continuidad del problema durante los "gobiernos progresistas" (Kessler 2014). 
accesible para la mayoría de los habitantes), la urbanización habilitaba otras posibilidades a través de un trabajo colectivo local sostenido estatalmente.

Como "emblema" de las políticas públicas kirchneristas, la urbanización de Villa Torres permite dar cuenta de algunas características del Estado durante esta década. En parte como respuesta a la crisis de 2001, el kirchnerismo tomó una orientación igualadora que se contraponía con "los noventa". En algunas interpretaciones, podría señalarse cierta continuidad con el peronismo histórico, pero mostraba diferencias significativas tanto por la pluralidad de horizontes de derecho (más allá del trabajo como eje) como por la centralidad del accionar estatal y su fragmentación. En esta villa, se actualizó una visión del ascenso social vinculado a la casa propia a la vez que se produjo un modo singular de hacerlo posible, circunscripta localmente, respaldada políticamente e inestable a lo largo del tiempo. Esta modalidad de articulación política está asociada con (y reforzó) la acumulación de heterogeneidades dentro de las clases populares (Semán y Ferraudi Curto 2016). Implicó un aprendizaje por parte de los actores de las condiciones en las que se ha consolidado la democracia en Argentina, a partir del cual lograron apropiarse de las políticas públicas disponibles después de 2001 o, como dice José, "aprovechar la oportunidad". Pero significó una mejoría relativa acotada localmente en un contexto de deterioro de largo plazo de las condiciones de vida.

El "problema de los jóvenes" condensa este proceso. Para estirar (y cuestionar) los límites de lo posible, las respuestas locales se apoyan en las diferentes políticas estatales y muestran moralidades locales plurales. Así como al demandar la urbanización, aquí también el párroco fue central en la problematización del asunto y la elaboración de una respuesta colectiva frente al mismo. Si desde los medios de comunicación los jóvenes de clases populares aparecen más bien como amenaza, localmente la cuestión consistió en "rescatarlos" a partir de una combinación de valores de la familia y de la esquina, tomando las figuras de la madre y del chorro como respaldo a partir de una valoración de la propia historia barrial. Articuladas con un horizonte de formación e inserción laboral inestable, estas acciones contribuyeron a legitimar a la urbanización, tanto dentro como fuera del barrio. Pero también generaron críticas y disidencias. Mientras la cuestión de la "politización" aparecía como un cuestionamiento frecuente (que escuché desde mi primera visita al barrio en 2007), la frontera entre "trabajadores" y "vagos" apareció más claramente hacia fines del kirchnerismo. A la vez, las disidencias buscaban desestabilizar los límites de lo posible a partir de la puesta en cuestión de dos instituciones centrales en la vida local: la iglesia y la policía. En ello, también interpelaban la valoración diferencial de las muertes jóvenes, un supuesto que los esfuerzos por "rescatarlos" (implícitamente) contribuían a sostener.

Finalmente, el Estado como urbanización convive con otras caras del Estado: por un lado, la multiplicación de políticas asistenciales enfocadas 
(y la importancia de los "jóvenes" como beneficiarios específicos) incorporó una lógica de derechos universalista y su inserción en tramas locales (que exceden el barrio) favoreció la visibilización de voces disidentes; por otro lado, tanto la urbanización como estas iniciativas se constituían en respuesta a un modo de presencia estatal más ubicuo, sostenido en la violencia, que amenazaba la vida de los jóvenes. Si bien la urbanización ha traído esperanzas, el futuro aparece incierto.

\section{BIBLIOGRAFÍA}

Alvarado, Sara, y Pablo Vommaro (comps.), 2010, Jóvenes, Cultura y Política en América Latina: Algunos Trayectos de Sus Relaciones, Experiencias y Lecturas (1960-2000). Rosario, Homo Sapiens.

BAIRD, Adam, y Dennis RODGERS, 2015, "Understanding gangs in contemporary Latin America", en Scott Decker y David Pyrooz (comps.), Handbook of Gangs and Gang Responses. Nueva York, Wiley, 478-502.

BERMÚDEZ, Natalia, 2014, "Moralidades de la inseguridad", en Natalia Bermúdez, y Malena E. Previtali, Merodear la Ciudad: Miradas Antropológicas sobre Espacio Urbano e Inseguridad en Córdoba. Córdoba, FFyH, 97-120.

BOURDIEU, Pierre, 1990, "La 'juventud' no es más que una palabra”, en Sociología y Cultura. México, DF, Grijalbo, 163-174.

CAMAROTTI, Ana, y Martín GÜELMAN, 2017, "Historia de los tratamientos para los consumos de drogas", en Ana Camarotti, Pablo Di Leo y Daniel Jones (comps.), Entre Dos Mundos: Abordajes Religiosos y Espirituales de los Consumos de Drogas. Buenos Aires, Teseo, 27-72.

CASAL, Joaquim, Maribel GARCÍA, y Rafael MERINO, 2015, "Pasado, presente y futuro de los estudios sobre las transiciones de los jóvenes", Revista de Estudios de Juventud, 110 : 69-81.

CHAVES, Mariana, 2005, "Juventud negada y negativizada: representaciones y formaciones discursivas vigentes en la Argentina contemporánea", Última Década, 13 (23): 9-32.

CHAVES, Mariana, 2009: "Investigaciones sobre juventudes en la Argentina: estado del arte en ciencias sociales 1983-2006", Papeles de Trabajo, 2 (5): 1-111.

DIEZ, Patricia, 2009, "Mecha en el barrio: situaciones dilemáticas y drama social entre demandas morales", en Alejandro Grimson, Cecilia Ferraudi Curto y Ramiro Segura (comps.), La Vida Política en los Barrios Populares de Buenos Aires. Buenos Aires, Prometeo, 85-102.

FERRAUDI CURTO, Cecilia, 2014, Ni Punteros ni Piqueteros. Urbanización y Política en Una Villa del Conurbano Bonaerense. Buenos Aires, Gorla.

FERRAUDI CURTO, Cecilia; Martina MORICONI, y Adrián PERALTA, 2017, "Informe Programa Envión-Podés", mimeo. 
FIRTH, Raymond, 1971 , "Criterios morales y organización social”, en Raymond Firth, Elementos de Antropología Social. Buenos Aires, Amorrortu, 201-233.

GAYOL, Sandra, y Gabriel KESSLER, 2017, "Cuando las muertes transforman: la lucha contra las violencias estatales en la Argentina reciente", Anuario IEHS, 32 (2): 27-46.

GENTILE, Florencia, 2011 a, "Los procedimientos discursivos para la construcción mediática de la figura del joven pobre y delincuente: el 'caso Jonathan' ”, Última Década, 19 (34): 93-119.

GENTILE, Florencia, 201 lb, "Niños, ciudadanos y compañeritos: un recorrido por los distintos criterios para el trabajo de inclusión social de niños y adolescentes de sectores vulnerables", en Isabella Cosse et al. (comps.), Infancias: Políticas y Saberes en Argentina y Brasil (siglos XIX y XX). Buenos Aires, Teseo, 265-286.

GENTILE, Florencia, 2017, Biografías Callejeras: Cursos de Vida de Jóvenes en Condiciones de Desigualdad. Buenos Aires, Grupo Editor Universitario.

GRINBERG, Julieta, 2013, “La recepción de los 'derechos del niño’ en Argentina: trayectorias de activistas y conformación de una nueva causa en torno de la infancia”, Virajes, 15 (1): 299-325.

Grossberg, Lawrence, 2005, Caught in the Crossfire: Kids, Politics and America's Future. Boulder, CO, Paradigm.

KESSLER, Gabriel, 2004, Sociología del Delito Amateur. Buenos Aires, Paidós.

KESSLER, Gabriel, 2009, El Sentimiento de Inseguridad: Sociología del Temor al Delito. Buenos Aires, Siglo XXI.

KESSLER, Gabriel, 2014, Controversias sobre la Desigualdad: Argentina, 2003-2013. Buenos Aires, FCE.

MANZANO, Valeria, 2017, La Era de la Juventud en Argentina. Buenos Aires, FCE.

MíGUEZ, Daniel, 2002, "Rostros del desorden: Fragmentación social y la nueva cultura delictiva en sectores juveniles”, en Sandra Gayol y Gabriel Kessler (comps.), Violencias, Delitos y Justicias en la Argentina. Buenos Aires, Manantial/UNGS, 313-338.

PEIRANO, Mariza, 1997, "Antropologia política, ciência política e antropologia da política", Série Antropologia, 231: 15-26.

PITA, Victoria, 2010, Formas de Morir y Formas de Vivir: El Activismo contra la Violencia Policial. Buenos Aires, Editores del Puerto.

PITT-RIVERS, Julian, 1989, Un Pueblo de la Sierra: Grazalema. Madrid, Alianza.

RAPOSO, Otávio, y Guilhermo ADERALDO, 2019, "Políticas públicas e produção artístico-cultural entre jovens das periferias de Lisboa e São Paulo”, Etnográfica, 23 (1): 109 -132 .

ROSEBERRY, William, 1994, "Hegemony and the language of contention", en Gilbert Joseph y Daniel Nugent (comps.), Everyday Forms of State Formation: Revolution and the Negotiation of Rule in Modern Mexico. Durham/Londres, Duke University Press, 355-366.

RUBINICH, Lucas, 1998, “Con los pies en la tierra': notas sobre dos experiencias de campo”, Apuntes de Investigación del CECyP, 2/3: 151-162.

SEMÁN, Pablo, y Cecilia FERRAUDI CURTO, 2016, "Sectores populares”, en Gabriel Kessler (comps.), La Sociedad Argentina Hoy: Radiografía de Una Nueva Estructura. Buenos Aires, Siglo XXI, 141-162.

VAN RAAP, Valeria, 2016, "Juventudes y desigualdades en la Argentina: notas para el debate en torno a la construcción de la problemática juvenil”, en Pablo Vommaro, Juventudes y Desigualdades en América Latina y el Caribe. Buenos Aires, Clacso, 167-186. 
VÁZQUEZ, Melina, 2013, "En torno a la construcción de la juventud como causa pública durante el kirchnerismo: principios de adhesión, participación y reconocimiento", Revista Argentina de Estudios de Juventud, 1 (7): 1-25.

VILLALTA, Carla, y Valeria LLOBET, 2015, "Resignificando la protección: los sistemas de protección de derechos de niños y niñas en Argentina", Revista Latinoamericana de Ciencias Sociales, Niñez y Juventud, 13 (1): 167-180.

WACQUANT, Loïc, 2010, Castigar a los Pobres: El Gobierno Neoliberal de la Inseguridad Social. Barcelona, Gedisa.

ZARAZAGA, Rodrigo, 2017, "El Estado Golem”, en Rodrigo Zarazaga y Lucas Ronconi (comps.), Conurbano Infinito: Actores Políticos y Sociales, entre la Presencia Estatal y la Ilegalidad. Buenos Aires, Siglo XXI/OSDE, 9-17.

Receção da versão original / Original version

2018/03/01

Aceitação / Accepted

$2018 / 06 / 27$

Pré-publicação online / Pre-published online

$2020 / 07 / 16$ 